\title{
Optimal design and planning of biodiesel supply chain network: a scenario-based robust optimization approach
}

\author{
M. Rezaei ${ }^{1}$ 'S. K. Chaharsooghi ${ }^{1}$ A. Husseinzadeh Kashan ${ }^{1} \cdot$ R. Babazadeh ${ }^{2}$
}

Received: 3 July 2019 / Accepted: 19 August 2019 / Published online: 30 August 2019

(c) The Author(s) 2019

\begin{abstract}
Effective design of biodiesel supply chain network can reduce many of its high production costs. There are various uncertain parameters in real world that if ignored may greatly affect the optimal configuration of the designed biodiesel supply chain. Scenario planning is a powerful tool which can help the decision makers for long-term planning under uncertainties. Therefore, in this paper, a scenario-based robust optimization model is presented for designing the biodiesel supply chain networks under uncertainties. Some of the parameters including demand, supply, costs, and environmental impacts have uncertain nature. For the first time, in this study, the values of these uncertain parameters are estimated by a proposed scenario-planning method. The presented scenario-planning approach is based on cross-impact analysis and visualization methods. Non-edible sources such as Jatropha, Norouzak, and waste cooking oil are considered as raw materials of biodiesel production, and for the first time Norouzak has been used as one of the sources in designing biodiesel supply chain. In addition, an environmental constraint is considered and the environmental impacts of all processes are obtained by Eco-indicator 99 method. The presented model can determine the number, location, and capacity of the facilities. The proposed model is implemented in a real case study in Iran for a 7-year planning horizon. The results show the effectiveness of the presented approach in designing the biodiesel supply chain networks under uncertainties.
\end{abstract}

Keywords Bioenergy $\cdot$ Biodiesel $\cdot$ Supply chain $\cdot$ Sustainable development $\cdot$ Scenario planning $\cdot$ Scenario-based robust optimization

\section{Introduction}

Nowadays, energy plays an important role in the development of societies. Sustainable energy is a form of energy that is produced and consumed in a way that ensures all social, economic, and environmental dimensions. In this regard, renewable energy has a direct relationship with sustainable development through its impact on human development and productivity and economics [1].

After coal and gas, biomass is the third-highest source of primary energy worldwide [2,3]. Biofuels are fuels produced from biomass sources which have a significant potential for reducing environmental pollutions [4]. Biodiesel

$\triangle$ S. K. Chaharsooghi

skch@modares.ac.ir

1 School of Industrial and Systems Engineering, Tarbiat Modares University, Tehran, Iran

2 Faculty of Engineering, Urmia University, Urmia, West Azerbaijan Province, Iran presents a competitive advantage compared to petrodiesel, because it has a high field of applicability in the existing car fleet, as many of its attributes and characteristics are like those of petrodiesel [5].

One of the main challenges in developing these types of energy is their high cost. The most important of these costs are logistics costs. If the supply chain of these energies is designed optimally, many of these costs can be reduced, so that their production will be economical.

The world is full of uncertainties that if we ignore them, the proposed model will be significantly different from reality. In the design of the supply chain network, many of the parameters have uncertain nature. Certainty assumption of the parameters leads to a non-optimized solution. Scenario analysis is an effective method for planning under uncertainty conditions. The scenarios provide a comprehensive overview of the environment and consider the interactions of trends and events in the future [6].

In this study, a scenario-based robust optimization model is proposed to design a biodiesel supply chain network under 
uncertainty. The presented model is implemented in a real case study in Iran. Although Iran has large reserves of fossil fuels, due to the finitude and the environmental pollution caused by these fuels, it is unavoidable to develop renewable energy resources. Iran has a high potential for renewable energies, of which one of the most important is biomass energy. Biodiesel, which is a good alternative to petrodiesel, can partly reduce air pollution in large cities. One of the problems associated with the development of biodiesel in Iran is its expensive price compared to other fossil fuels. If the biodiesel supply chain network is designed efficiently, many of these costs will be greatly reduced.

Most researches have been carried out on producing biodiesel from edible sources or sources that require high water and fertile soil for cultivation [7]. Since almost $80 \%$ of edible oils in Iran are obtained through imports, it is not justifiable to use the sources of edible oils for biodiesel production [8]. In addition, semi-desert with salty soil and arid climate has the most potential for exploitation in Iran [7]. Thus, it is necessary to use sources that are compatible with Iran's climate and have little water requirement. Therefore, Jatropha and Norouzak (Salvia leriifolia), which are non-edible and also compatible with the climate of Iran, are suitable for biodiesel production. In addition, another problem with the use of edible sources to produce biodiesel is their relatively high production costs. In this regard, waste cooking oil (WCO) which is less costly than edible oils, can be used to produce biodiesel. Therefore, in this study, Jatropha, Norouzak, and waste cooking oil are used as biodiesel production sources. In addition, due to the high air pollution problems in the big and industrial cities of the country, an environmental constraint is considered in the proposed model.

In this paper, a mathematical programming model based on robust optimization method is presented for designing the biodiesel supply chain. In this model, some parameters such as demand, supply, costs, and environmental impacts are assumed uncertain. In the robust optimization model, the value of uncertain parameters must be estimated in each scenario and the probability of the scenarios must be determined. Therefore, in this study, a scenario-planning approach which is based on cross-impact analysis and visualization methods is presented to design the diesel scenarios. By this scenarioplanning method, the probability of occurrence of the designed scenarios is determined and, based on the conditions and structure of the scenarios, the uncertain parameters are estimated in each scenario over the time planning horizon. The algorithm of the presented approach is shown in Fig. 1.

\section{Literature review}

In this section, similar studies on the topic of the research will be reviewed.



Fig. 1 The algorithm of the presented approach

Various modeling approaches are used by researchers for designing biofuel supply chain, including simulation, mathematical programming, and GIS [9]. The mathematical programming models are the most used methods in the literature [10]. The related researches to our work are discussed in the following.

Ahn et al. [11] presented a deterministic mathematical programming model for the design of a biodiesel supply chain network. This model determined the number and location of supply centers and biorefineries with the goal of minimizing the total cost. Leão et al. [12] developed a mathematical model for designing the biodiesel supply chain from castor oil in Brazil. They considered the production, crushing of oilseeds, and transportation along the planning horizon.

In some studies, non-linear models were used in designing the biodiesel supply chain network. For example, Ren et al. [13] proposed a mixed integer non-linear programming model that used the energy sustainability index to measure the sustainability of the biodiesel supply network. They developed a multi-product model in which multiple transport modes, multiple locations for biorefineries, and distribution centers were considered.

Several papers considered multi-objective models for designing the biodiesel supply chains. Rincón et al. [14] proposed a multi-objective model for designing the biodiesel supply chain network from oil palm in Columbia. The goal of this model was to minimize the total costs and the total emissions across the supply chain. Orjuela-Castro et al. [15] developed a multiobjective model for designing a biodiesel supply chain network that took into account all three aspects of sustainable development. They analyzed the relationship among the economic, environmental, and social dimensions in the biodiesel supply chain.

One of the important challenges in designing a biofuel supply chain is the uncertainty that exists in the supply chain. If 
these parameters are assumed deterministic, the designed supply chain will be far away from the real world $[16,17]$. There are various approaches to dealing with uncertainty in the literature, which are used according to the type of data uncertainty.

In some studies, fuzzy mathematical programming approaches were applied. For example, Ubando et al. [18] developed a fuzzy mathematical programming model for designing a biodiesel supply chain network. This was a multi-objective model that considered multi-regions. Many papers used stochastic models in designing a biodiesel supply chain under uncertainty. Senna et al. [19] presented a two-stage and a three-stage stochastic model for designing the castor-based biodiesel supply chain. The results of comparing these formulations showed that the total logistic cost in the three-stage model was lower. There is a growing body of literature that applies robust optimization methods for biodiesel supply chain network design. Zhang et al. [20] proposed a robust mixed integer linear model to design a biodiesel supply chain network under demand and supply uncertainty. In this research, multiple objectives (economic, environmental, and social) were considered in the design of the supply chain. They applied the genetic algorithm to solve this model.

In this study, a scenario-based robust optimization model is presented to design a biodiesel supply chain network under uncertainty. In the proposed model, some parameters including biodiesel demand, supply of WCO, costs (fixed, variable, production, inventory holding, and transportation costs), and environmental impact parameters have uncertain nature. To estimate the values of these uncertain parameters in this study, for the first time a scenario-planning approach is presented, which is based on cross-impact analysis and visualization methods. Non-edible sources including Jatropha, Norouzak, and WCO are considered as sources of biodiesel production, and for the first time Norouzak is used as one of the raw materials in designing biodiesel supply chain. In addition, the environmental impacts of the processes are calculated through SimaPro software. The amount of $\mathrm{CO}_{2}$ emissions from the processes through the constructed supply chain must not exceed the considered upper bound. To assess the effectiveness and performance of the proposed model, it is applied in a real case study in Iran for a 7-year planning horizon.

\section{Scenario-based robust optimization formulation}

Mathematical programming models are a powerful tool for designing supply chain networks. Since there are many uncertainties in the real world, some mathematical programming models are developed in the literature for designing supply chains under uncertainty. In this section, robust optimization method, which is developed for designing the proposed biodiesel supply chain network under uncertainty, will be explained.

The robust optimization method is presented by Mulvey et al. [21]. This is one of the most appropriate approaches to planning in the conditions that there are risks and disturbances in the surrounding environment. There are two kinds of constraints in a robust optimization: structural constraint and control constraint. The control constraints are influenced by noisy data, while in structural constraints there is no noise in the input data. In addition, there are two types of variables in a robust optimization: design and control. While the value of design variables can be determined before the scenario realization, the value of control variables can be changed according to various simulations of the uncertain parameters [22].

A scenario-based robust optimization model based on the mathematical programming problem can be stated as follows:

Min $\sigma\left(x, y_{1}, y_{2}, \ldots, y_{s}\right)$,

$A x=b$,

$B_{s} x+C_{s} y_{s}=e_{s} \quad \forall s$,

$x \geq 0, \quad y_{s} \geq 0$,

where $x$ and $y$ are vectors of design and control variables, respectively. $b$ and $e$ are parameter vectors, and $A, B$, and $C$ are parameter matrices. As shown in the above-mentioned equations, some parameters $(b, A)$ are known deterministically and the others $(e, B, C)$ are uncertain. Equation 2 is a structural constraint that there is no noise in its coefficients, while Eq. 3 is a control constraint that its parameters are influenced by noise. In the robust optimization programming, there are a set of scenarios. The control variable is denoted as $y_{s}$ and, similarly, uncertain coefficients are denoted as $e_{s}, B_{s}$, and $C_{s}$ for scenario $s$ with probability $p_{s}$, which indicates the probability of occurrence of scenario $s$.

Assume $\xi$ shows $f(x, y)$ that is a benefit or cost function. Therefore, $\xi_{s}=f\left(x, y_{s}\right)$ for each scenario. If the variance for $\xi_{s}$ is high, the risk of decision making will be high. In fact, in these conditions, small changes in the uncertain parameters will cause large changes in the objective function. Mulvey et al. [21] proposed Eq. 5 to represent the solution robustness.

$\sigma(\cdot)=\sum_{s} p_{s} \xi_{s}+\gamma \sum_{s} p_{s}\left(\xi_{s}-\sum_{s^{\prime}} p_{s^{\prime}} \xi_{s^{\prime}}\right)^{2}$,

where in the above-mentioned equation, $p_{s}$ is the associated probability, and $\gamma$ is the weight placed on solution variance. When $\gamma$ increases, the solution will be less sensitive to changes in the uncertain parameters.

As shown in Eq. 5, there is a quadratic term in the formulation. So this model is non-linear and requires a long time of computation. In this regard, $\mathrm{Yu}$ and $\mathrm{Li}$ [23] proposed the 
following form (absolute deviation instead of the quadratic form):

$\sigma(\cdot)=\sum_{s} p_{s} \xi_{s}+\gamma \sum_{s} p_{s}\left|\xi_{s}-\sum_{s^{\prime}} p_{s^{\prime}} \xi_{s^{\prime}}\right|$.

According to the absolute deviation form, Eq. 6 is still non-linear. To solve this problem, Pan and Nagi [24] used two non-negative deviational variables and proposed the following equations. Indeed, instead of minimizing the absolute deviation form in Eq. 6, these two introduced positive variables are minimized subject to the main constraints and the added soft constraint.

$$
\begin{aligned}
& \operatorname{Min} \sum_{s} p_{s} \xi_{s}+\gamma \sum_{s}\left(Q_{s}^{+}+Q_{s}^{-}\right), \\
& \xi_{s}-\sum_{s^{\prime}} p_{s^{\prime}} \xi_{s^{\prime}}=Q_{s}^{+}-Q_{s}^{-} \quad \forall s, \\
& Q_{s}^{+}, Q_{s}^{-} \quad \geq 0 .
\end{aligned}
$$

\section{The proposed biodiesel supply chain network}

Before designing the mathematical programming model, it is necessary to define the structure of the supply chain and explain its assumptions. The structure of the proposed supply chain network is shown in Fig. 2. It is a four-echelon, multiproduct, multi-period model under uncertainty. As shown in Fig. 1, the Jatropha yields are transported from their cultivation areas to oil extraction centers. Similarly, the Norouzak yields are transported from their cultivation areas to the oil extraction centers. Jatropha and Norouzak oil are obtained at oil extraction centers and then shipped to refineries. Waste cooking oils are also collected from supply centers and shipped to refineries for pretreating. In the refineries, the biodiesel is produced from Jatropha oil, Norouzak oil, and pretreated WCO. Then, the produced biodiesel is transported to distribution centers. Finally, biodiesel is transported from distribution centers to consumer locations for blending with petrodiesel.

\section{Assumptions}

The assumptions of the proposed supply chain network are as follows:

- Transportations are performed through two modes (road and rail).

- All biodiesel demands must be satisfied (shortage is not allowed).

- The biodiesel consumer centers are known (7 cities).

- The candidate areas for cultivating Jatropha and Norouzak, and all the other facilities' potential locations are known.
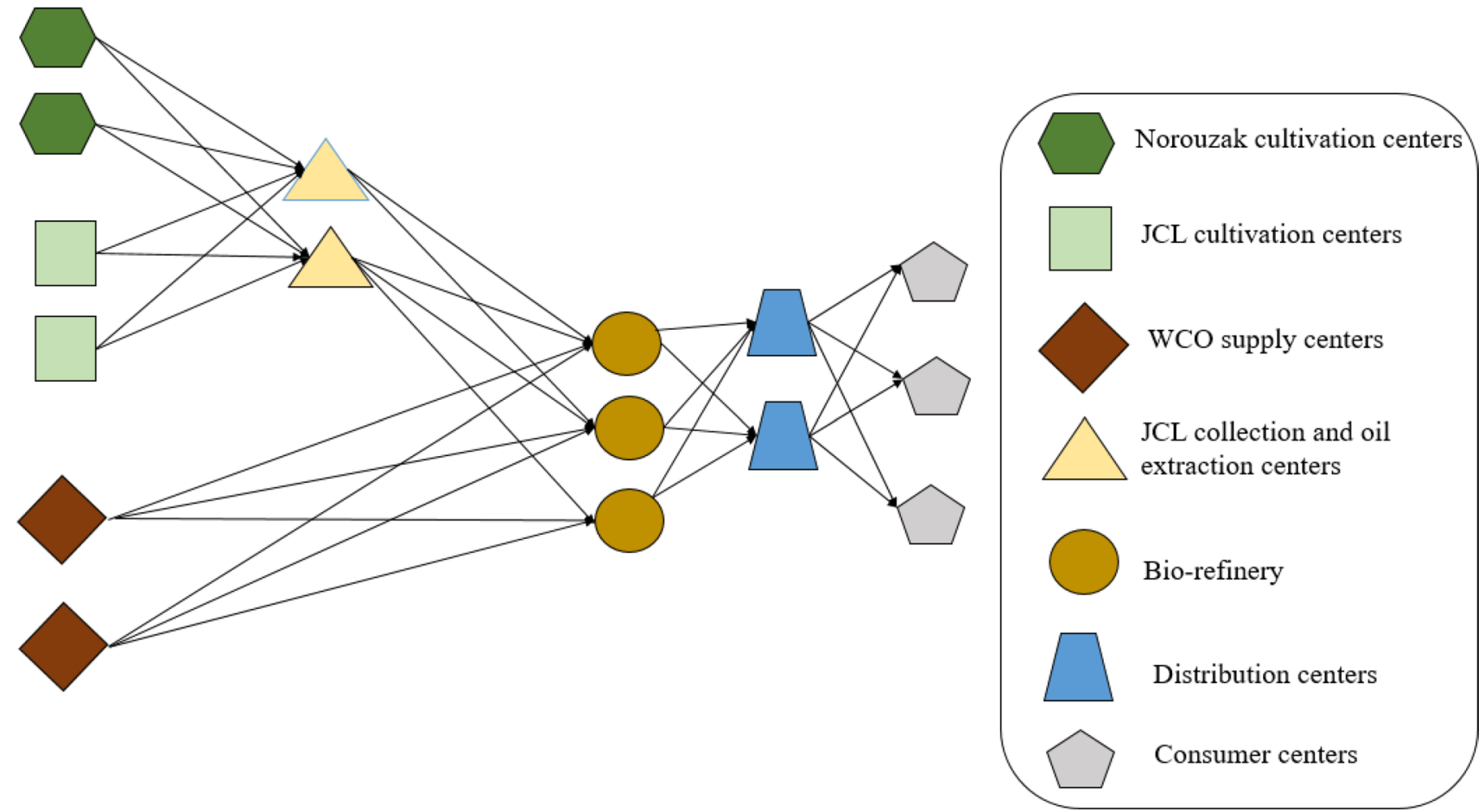

Fig. 2 Structure of the proposed biodiesel supply chain network 
- The capacity of the Jatropha and Norouzak cultivation centers, oil extraction centers, and distribution centers are determined through continuous decision variables.

- The capacity of refineries is accounted for by adding the determined capacity options to the initial considered capacity.

- Some parameters including biodiesel demand, supply of WCO, costs (fixed, variable, production, inventory holding, and transportation costs), and environmental factors are assumed uncertain. All of the other parameters have deterministic nature.

- Transshipment of biodiesel among the distribution centers is not allowed.

\section{Mathematical programming model}

In this section, the mathematical programming model developed for designing the biodiesel supply chain based on the robust optimization method will be introduced. This model is designed according to the specific characteristics of the case study. Detailed notation of indices, parameters, and variables that are used in the proposed model are given in the nomenclature in "Appendix". The objective function and constraints of the proposed model are described in the following.

\section{Objective function}

The objective function of the presented biodiesel supply chain minimizes the total costs: this consists of fixed opening costs (FC), variable opening costs (VC), production costs (PC), inventory holding costs (IC), and transportation costs (TC).

$\mathrm{FC}_{s}$ (fixed opening costs)

$$
\begin{aligned}
= & \sum_{j} \mathrm{FC}_{j s}^{1} v_{j}^{1}+\sum_{n} \mathrm{FC}_{n s}^{2} v_{n}^{2}+\sum_{e} \mathrm{FC}_{e s}^{3} s_{e}^{3}+\sum_{r} \sum_{t} \mathrm{FC}_{r s}^{4}\left(v_{r t}^{4}-v_{r, t-1}^{4}\right) \\
& +\sum_{o} \sum_{r} \sum_{t} \mathrm{FO}_{\text {orts }}\left(c o_{o r t}-c o_{o r, t-1}\right)+\sum_{k} \mathrm{FC}_{k s}^{5} v_{k}^{5} .
\end{aligned}
$$

$\mathrm{VC}_{s}$ (variable opening costs)

$$
\begin{aligned}
= & \sum_{j} \mathrm{VC}_{j s}^{1} q_{j}^{1}+\sum_{n} \mathrm{VC}_{n s}^{2} q_{n}^{2}+\sum_{e} \sum_{t} \mathrm{VC}_{e t s}^{3} q_{e t}^{3}+\sum_{r} \sum_{t} \mathrm{VC}_{r t s}^{4} q_{r t}^{4} \\
& +\sum_{k} \sum_{t} \mathrm{VC}_{k t s}^{5} q_{k t}^{5} .
\end{aligned}
$$

$\mathrm{PC}_{s}$ (production costs )

$$
\begin{aligned}
= & \sum_{j} \sum_{t} \mathrm{PC}_{j t s}^{1} p_{j t s}^{1}+\sum_{n} \sum_{t} \mathrm{PC}_{n t s}^{2} p_{n t s}^{2}+\sum_{w} \sum_{t} \mathrm{PC}_{w t s}^{3} \mathrm{WS}_{w t s} \\
& +\sum_{e} \sum_{t} \mathrm{PC}_{e t s}^{4} p_{e t s}^{4}+\sum_{e} \sum_{t} \mathrm{PC}_{e t s}^{5} p_{e t s}^{5}+\sum_{r} \sum_{t} \mathrm{PC}_{r t s}^{6} p_{r t s}^{6} \\
& +\sum_{r} \sum_{t} \mathrm{PC}_{r t s}^{7} p_{r t s}^{7} .
\end{aligned}
$$

$\mathrm{IC}_{s}$ (Inventory holding costs )

$$
\begin{aligned}
= & \sum_{e} \sum_{t} \mathrm{IC}_{e t s}^{1} h_{e t s}^{1}+\sum_{e} \sum_{t} \mathrm{IC}_{e t s}^{2} h_{e t s}^{2}+\sum_{r} \sum_{t} \mathrm{IC}_{r t s}^{3} h_{r t s}^{3} \\
& +\sum_{k} \sum_{t} \mathrm{IC}_{k t s}^{4} h_{k t s}^{4}
\end{aligned}
$$

$\mathrm{TC}_{S}$ (transportation costs)

$$
\begin{aligned}
& =\sum_{j} \sum_{l} \sum_{e} \sum_{t} \mathrm{TC}_{j l e t s}^{1} f_{j l e t s}^{1}+\sum_{n} \sum_{l} \sum_{e} \sum_{t} \mathrm{TC}_{\text {nlets }}^{2} f_{\text {nlets }}^{2} \\
& +\sum_{w} \sum_{l} \sum_{r} \sum_{t} \mathrm{TC}_{\text {wlrts }}^{3} f_{\text {wrts }}^{3} \\
& +\sum_{e} \sum_{l} \sum_{r} \sum_{t} \mathrm{TC}_{\text {elrts }}^{4} f_{\text {elrts }}^{4}+\sum_{e} \sum_{l} \sum_{r} \sum_{t} \mathrm{TC}_{\text {elrts }}^{5} f_{\text {elrts }}^{5} \\
& +\sum_{r} \sum_{l} \sum_{k} \sum_{t} \mathrm{TC}_{\text {rlkts }}^{6} f_{\text {rlkts }}^{6}+\sum_{k} \sum_{l} \sum_{u} \sum_{t} \mathrm{TC}_{\text {kluts }}^{7} f_{\text {kluts }}^{7} .
\end{aligned}
$$

Equations 10 and 11 are the fixed and variable costs for establishing the facilities. Equation 12 represents the production costs of different products (Jatropha, Norouzak, WCO, Jatropha oil, Norouzak oil, pretreated WCO, and biodiesel). Equation 13 shows the inventory holding costs of the facilities (oil extraction centers, refinery centers, and distribution centers). Finally, Eq. 14 represents the total transportation costs of shipping different products between the various facilities. Therefore, the objective function of the proposed supply chain network is shown by Eq. 15 .

Min $\sum_{s} p_{s}\left(\mathrm{FC}_{s}+\mathrm{VC}_{s}+\mathrm{PC}_{s}+\mathrm{IC}_{s}+\mathrm{TC}_{s}\right)+\gamma \sum_{s}\left(Q_{s}^{+}+Q_{s}^{-}\right)$.

The first term in the objective function (Eq. 15) is the mean value cost and the second term is the variance of the total cost.

\section{Constraints}

In this section, all the constraints that are used in the mathematical model will be explained. As stated in the previous section, Eq. 16 is used to linearize the initial objective function.

$$
\begin{aligned}
& \left(\mathrm{FC}_{s}+\mathrm{VC}_{s}+\mathrm{PC}_{s}+\mathrm{IC}_{s}+\mathrm{TC}_{s}\right) \\
& \quad-\sum_{s^{\prime}} p_{s^{\prime}}\left(\mathrm{FC}_{s^{\prime}}+\mathrm{VC}_{s^{\prime}}+\mathrm{PC}_{s^{\prime}}+\mathrm{IC}_{s^{\prime}}+\mathrm{TC}_{s^{\prime}}\right) \\
& \quad=Q_{s}^{+}-Q_{s}^{-} \quad \forall s .
\end{aligned}
$$

Constraint 17 ensures that the amount of biodiesel transported from refineries to a consumer center is equal to its demand. Constraint 18 represents that all Jatropha seeds 
are moved to oil extraction sites in each time period. Similarly, Constraints 19 ensures that all Norouzak products are moved to oil extraction sites. Constraint 20 states that all WCO are collected and transported from WCO supply sites to refineries.

$\sum_{k} \sum_{l} f_{\text {kluts }}^{7}=\mathrm{DB}_{u t s} \quad \forall u, t, s$,

$\sum_{l} \sum_{e} f_{j l e t s}^{1}=p_{j t s}^{1} \quad \forall j, t, s$,

$\sum_{l} \sum_{e} f_{\text {nlets }}^{2}=p_{n t s}^{2} \quad \forall n, t, s$

$\sum_{l} \sum_{r} f_{w l r t s}^{3}=\mathrm{WS}_{w t s} \quad \forall w, t, s$.

Equation 21 shows the amount of Jatropha products obtained from Jatropha cultivation areas. Similarly, Eq. 22 represents the amount of Norouzak products obtained from Norouzak cultivation areas. Equations 23 and 24 state the amount of oil extracted from Jatropha and Norouzak in oil extraction centers, respectively. Equation 25 shows the amount of pretreated WCO in the refineries. Equation 26 represents the amount of biodiesel produced from Jatropha oil, Norouzak oil, and pretreated WCO in the refineries.

$p_{j t s}^{1}=\alpha_{j t}^{1} q_{j}^{1} \quad \forall j, t, s$,

$p_{n t s}^{2}=\alpha^{2} q_{n}^{2} \quad \forall n, t$

$p_{e t s}^{4}=\beta^{1} \sum_{j} \sum_{l} f_{j l e t s}^{1} \quad \forall e, t, s$,

$p_{\text {ets }}^{5}=\beta^{2} \sum_{n} \sum_{l} f_{\text {nlets }}^{2} \quad \forall e, t, s$,

$p_{r t s}^{6}=\beta^{3} \sum_{g w} \sum_{l} f_{w l r t s}^{3} \quad \forall r, t, s$,

$p_{r t s}^{7}=\varphi^{1} \sum_{e} \sum_{l} f_{\text {elrts }}^{4}+\varphi^{2} \sum_{e} \sum_{l} f_{\text {elrts }}^{5}+\varphi^{3} p_{r t s}^{6} \quad \forall r, t, s$.

Equation 27 states that the inventory level of Jatropha seeds in oil extraction sites at each period is equal to its inventory level at the previous period plus the amount of Jatropha moved from its cultivation areas minus the amount of Jatropha converted to oil and moved to refineries. Similarly, Eq. 28 provides the inventory balance level at oil extraction sites with respect to Norouzak products. Finally, Eqs. 29 and 30 show the inventory balance level at refineries and distribution sites, respectively. $h_{e t s}^{1}=h_{e, t-1, s}^{1}+\sum_{j} \sum_{l} f_{j l e t s}^{1}-\left(\frac{1}{\beta^{1}}\right) \sum_{l} \sum_{r} f_{\text {elrts }}^{4} \quad \forall e, t, s$,

$h_{e t s}^{2}=h_{e, t-1, s}^{2}+\sum_{n} \sum_{l} f_{n l e t s}^{2}-\left(\frac{1}{\beta^{2}}\right) \sum_{l} \sum_{r} f_{\text {elrts }}^{5} \quad \forall e, t, s$,

$h_{r t s}^{3}=h_{r, t-1, s}^{3}+p_{r t s}^{7}-\sum_{l} \sum_{k} f_{r l k t s}^{6} \quad \forall r, t, s$,

$h_{k t s}^{4}=h_{k, t-1, s}^{4}+\sum_{r} \sum_{l} f_{r l k t s}^{6}-\sum_{l} \sum_{u} f_{k l u t s}^{7} \quad \forall k, t, s$.

Equation 31 refers to a logical constraint. Equation 32 ensures that when a refinery is established, it will be active until the end of the period. Equation 33 also ensures that when a capacity is added, it will be active until the end of the period. Constraints 34 and 35 show the minimum and maximum allowable areas for cultivation of Jatropha and Norouzak, respectively. Minimum areas are applied for considering the advantage of economy of scale, and maximum areas are considered due to biodiversity concern. Constraints 36-38 indicate the minimum and maximum allowable capacity of oil extraction sites, refineries, and distribution sites, respectively.

Constraints 39 and 40 indicate the minimum number of locations that must be considered for the cultivation of Jatropha and Norouzak, respectively. This equation is for consideration of biodiversity. Constraints 41-43 show the maximum number of locations that can be considered for the oil extraction, refineries, and distribution centers. These equations are considered due to budget limitations.

Equations 44 and 45 indicate the amount of capacity expansion for oil extraction and distribution centers, respectively. Equation 46 calculates the total capacity of each refinery. As shown in Eqs. 44-46, the capacity of oil extraction centers and distribution centers is determined through continuous decision variables, while the capacity of refineries is accounted for by adding determined capacity options to the initial considered capacity.

$z_{\text {ort }} \leq v_{r t}^{4} \quad \forall o, r, t$,

$v_{r t}^{4} \leq v_{r, t+1}^{4} \quad \forall r, t$,

$z_{o r t} \leq z_{o r, t+1} \quad \forall o, r, t$,

$v_{j}^{1} L_{j}^{1} \leq q_{j}^{1} \leq v_{j}^{1} U_{j}^{1} \quad \forall j$,

$v_{n}^{2} L_{n}^{2} \leq q_{n}^{2} \leq v_{n}^{2} U_{n}^{2} \quad \forall n$, 


$$
\begin{aligned}
& v_{e}^{3} L_{e}^{3} \leq q_{e t}^{3} \leq v_{e}^{3} U_{e}^{3} \quad \forall e, t \\
& v_{r t}^{4} L_{r}^{4} \leq q_{r t}^{4} \leq v_{r t}^{4} U_{r}^{4} \quad \forall r, t \\
& v_{k}^{5} L_{k}^{5} \leq q_{k t}^{5} \leq v_{k}^{5} U_{k}^{5} \quad \forall k, t \\
& \sum_{j} v_{j}^{1} \geq \mathrm{MN}^{1}, \\
& \sum_{n} v_{n}^{2} \geq \mathrm{MN}^{2}, \\
& \sum_{e} v_{e}^{3} \leq \mathrm{MX}^{1}, \\
& \sum_{r} v_{r t}^{4} \leq \mathrm{MX}^{2} \quad \forall t, \\
& \sum_{k} v_{k}^{5} \leq \mathrm{MX}^{3}, \quad \forall r, \\
& q_{e t}^{3}=q_{e, t-1}^{3}+q e_{e t}^{1} \quad \forall e, t \\
& q_{k t}^{5}=q_{k, t-1}^{5}+q e_{k t}^{2} \quad \forall k, t \\
& q_{r t}^{4}=q_{r, t-1}^{4}+\mathrm{FW}_{r t}\left(v_{r t}^{4}-v_{r, t-1}^{4}\right)+\sum_{o} \mathrm{CW}_{o r t} z_{o r t} \quad \forall r, t
\end{aligned}
$$

Equation 47 requires that the amount of Jatropha and Norouzak shipped from their cultivation sites to each oil extraction site does not exceed its capacity. Equation 48 ensures that the amount of Jatropha oil, Norouzak oil, and WCO transported to refineries does not exceed their capacities. Similarly, Eq. 49 is a capacity constraint at distribution sites. Equations 50-52 are capacity constraints for inventory holding at oil extraction sites, refineries, and distribution sites, respectively. In other words, these equations enforce that the inventory level of each facility does not exceed its capacity.

$$
\begin{aligned}
& \sum_{j} \sum_{l} f_{j l e t s}^{1}+\sum_{n} \sum_{l} f_{\text {nlets }}^{2} \leq q_{e t}^{3} \quad \forall e, t, s, \\
& \sum_{w} \sum_{l} f_{w l r t s}^{3}+\sum_{e} \sum_{l} f_{\text {elrts }}^{4}+\sum_{e} \sum_{l} f_{\text {elrts }}^{5} \leq q_{r t}^{4} \quad \forall r, t, s,
\end{aligned}
$$

$\sum_{r} \sum_{l} f_{r l k t s}^{6} \leq q_{k t}^{5} \quad \forall k, t, s$

$h_{e t s}^{1}+h_{e t s}^{2} \leq q_{e t}^{3} \quad \forall e, t, s$, $h_{r t s}^{3} \leq q_{r t}^{4} \quad \forall r, t, s$,

$h_{k t s}^{4} \leq q_{k t}^{5} \quad \forall k, t, s$.

Equation 53 limits the amount of $\mathrm{CO}_{2}$ emissions from the processes through the constructed supply chain. In this equation, MGW is the maximum permitted global warming by the constructed supply chain. Determination of this parameter will be explained in the data-gathering section.

$\mathrm{EC}_{s}+\mathrm{EP}_{s}+\mathrm{ET}_{s}+\mathrm{EI}_{s} \leq \mathrm{MGW} \quad \forall s$.

This equation consists of environmental effect of opening the facilities (EC), production (EP), transportation (ET), and inventory holding (EI).

$$
\begin{aligned}
\mathrm{EC}_{s}= & \sum_{j} \mathrm{EC}_{s}^{1} \cdot q_{j}^{1}+\sum_{n} \mathrm{EC}_{s}^{2} \cdot q_{n}^{2}+\sum_{e} \sum_{t} \mathrm{EC}_{s}^{3} \cdot q_{e t}^{3} \\
& +\sum_{r} \sum_{t} \mathrm{EC}_{s}^{4} \cdot q_{r t}^{4}+\sum_{k} \sum_{t} \mathrm{EC}_{s}^{5} \cdot q_{k t}^{5}, \\
\mathrm{EP}_{s}= & \sum_{e} \sum_{t} \mathrm{EP}_{s}^{1} \cdot p_{e t s}^{4}+\sum_{e} \sum_{t} \mathrm{EP}_{s}^{2} \cdot p_{e t s}^{5}+\sum_{r} \sum_{t} \mathrm{EP}_{s}^{3} \cdot p_{r t s}^{7},
\end{aligned}
$$

$$
\begin{aligned}
\mathrm{ET}_{s}= & \sum_{j} \sum_{l} \sum_{e} \sum_{t} \mathrm{ET}_{j l e s}^{1} \cdot D_{j l e}^{1} \cdot f_{j l e t s}^{1}+\sum_{n} \sum_{l} \sum_{e} \sum_{t} \mathrm{ET}_{\text {nles }}^{2} \cdot D_{\text {nle }}^{2} \cdot f_{\text {llets }}^{2} \\
& +\sum_{n} \sum_{l} \sum_{e} \sum_{t} \mathrm{ET}_{\text {wlrs }}^{3} \cdot D_{\text {wlr }}^{3} \cdot f_{\text {wlrts }}^{3}+\sum_{e} \sum_{l} \sum_{r} \sum_{t} \mathrm{ET}_{\text {elrs }}^{4} \cdot D_{\text {elr }}^{4} \cdot f_{\text {elrts }}^{4} \\
& +\sum_{e} \sum_{l} \sum_{r} \sum_{t} \mathrm{ET}_{\text {elrs }}^{5} \cdot D_{\text {elr }}^{4} \cdot f_{\text {elrts }}^{5}+\sum_{r} \sum_{l} \sum_{k} \sum_{t} \mathrm{ET}_{r l k s}^{6} \cdot D_{r l k}^{5} \cdot f_{r l k s}^{6} \\
& +\sum_{k} \sum_{l} \sum_{u} \sum_{t} \mathrm{ET}_{\text {klus }}^{7} \cdot D_{\text {klu }}^{6} \cdot f_{\text {kluts }}^{7},
\end{aligned}
$$

$$
\begin{aligned}
\mathrm{EI}_{s}= & \sum_{e} \sum_{t} \mathrm{EI}_{s}^{1} \cdot h_{e t s}^{1}+\sum_{e} \sum_{t} \mathrm{EI}_{s}^{2} \cdot h_{e t s}^{2} \\
& +\sum_{r} \sum_{t} \mathrm{EI}_{s}^{3} \cdot h_{r t s}^{3}+\sum_{k} \sum_{t} \mathrm{EI}_{s}^{4} \cdot h_{k t s}^{4} .
\end{aligned}
$$

Equations 58 and 59 refer to binary and non-negative continuous decision variables, respectively.

$v_{j}^{1}, v_{n}^{2}, v_{e}^{3}, v_{r t}^{4}, v_{k}^{5}, z_{o r t} \in\{0,1\}$,

Continuous decision variables $\geq 0$.

\section{Data gathering}

In the previous section, the mathematical programming model developed in designing the proposed biodiesel supply chain network is presented. The presented model is applied in a case study in Iran. In this section, data of the parameters which are used in this model and where these data are extracted will be described. In the next section, the estimation of the uncertain parameters will be explained. 
The data of the parameters used in the presented method are achieved through historical data and also the scientific researches of the literature. In this study, non-edible sources which are compatible with Iran's climate conditions, i.e., Jatropha and Norouzak, are considered for biodiesel production. Babazadeh et al. [8] used a unified data envelopment analysis method to obtain suitable places for cultivating Jatropha in Iran. According to them, in this study 11 potential regions for cultivating Jatropha are considered. Similarly, seven regions compatible with Iran's climatic conditions are selected as candidate locations for cultivating Norouzak. In addition, waste cooking oil (WCO) is considered as a biodiesel source.

There are 30 cities in Iran. Therefore, 30 potential locations for supplying WCO are considered. The quantity of WCO produced in cities is obtained from the IFCO (www. ifco.ir). Similarly, 30 potential locations for oil extraction and 30 potential locations for distribution centers are considered. Large and industrial cities of Iran (9 cities) are taken into account as potential locations for establishing refineries. Cities with the most diesel consumption and high air pollution problems (7 locations) are selected as biodiesel consumer centers.

In addition, the time period of 7 years and two transportation modes are considered. Transportation of products between cities is performed by road and rail transportation modes. Road mode can be used among all cities, though rail mode can be used exclusively among 11 cities. Transportation cost among the locations is determined by multiplying the unit cost of transportation (extracted from [25]), in distance among them (taken from www.mrud.ir) for road mode, and (www.asiaseiraras.com) for rail mode). Also, conversion factor parameters are achieved from literature.

To calculate the environmental impacts of the processes, SimaPro 8 software equipped with Ecoinvent version 3 database is used. The values of these parameters are obtained in the standard conditions, while in the real world the conditions are not stable. Consequently, in the next section, the values are calculated according to the structure of the scenarios.

As mentioned in the previous section, in this study an environmental constraint is considered, so that the amount of $\mathrm{CO}_{2}$ emissions from the processes through the constructed supply chain must not exceed the upper bound (MGW). To determine the amount of MGW, the environmental objective function (left side of Eq. 53) is replaced with the cost objective function. After running the model, according to experts' opinions, the value of the environmental objective function is multiplied by 1.1 to obtain the MGW values.

In the proposed model, some uncertain parameters including biodiesel demand, supply of WCO, costs, and environmental impacts are taken into account. How to estimate these parameters will be explained in the next section.

\section{Scenario planning}

In the proposed biodiesel supply chain, there are some uncertain parameters including demand, supply, costs, and environmental impacts. In this study, a scenario-based robust optimization model is developed for designing the supply chain. As mentioned in the previous sections, in the robust optimization model the uncertain parameters must be estimated under each scenario and, also, the probability of scenarios must be determined. In this section, a scenario-planning method is presented to design the diesel scenarios. By this method, the probability of scenarios can be determined and the uncertain parameters will be estimated according to the conditions of each scenario.

Considering different options for the possible future will help to better plan the future [26]. It improves significantly the ability to face uncertainty [27]. Scenario analysis, as a prime method of futures studies, has long been applied by government planners, corporate executives, and military analysts to help the decision-making process under future uncertainty [28]. The advantage of scenarios is the selection of complex elements and combining them to present a story in a coherent, systematic, and comprehensive way.

Abbaszadeh et al. [29] presented a scenario analysis method for analyzing the future of Iran's oil. According to their work, in this study, based on cross-impact analysis (CIA) and visualization methods, some scenarios will be developed. Through cross-impact analysis, the relationships between trends will be determined to analyze them and consider their mutual consequences. Then, through visualization method, the designed scenarios will be introduced. Descriptions of these two methods are given in this section.

\section{Cross-impact analysis}

Cross-impact analysis (CIA) is used in determining the causal relationships between the most important trends and to obtain the probability of occurring of these events. This method is used for long-term forecasting of events and assumes that the occurrences of these events are not independent. In this method, the scenarios are designed according to the highest possible probabilities that are consistent with the estimates.

\section{Visualization}

Judgmental approaches which are mainly based on the judgment of one or more experts, are among the most used scenario-planning methods. Judgmental approaches can be supported by some methods including visualization, genius, role playing, etc. The ordering of individual perceptions involves 
visualization so that scenarios can be thought of as images or mental maps of the future in a story. Visualization uses meditative and relaxation methods for directing the mind to various aspects of the future.

\section{Diesel and biodiesel scenarios}

In this section, the developed scenario-planning method is presented. This method is a combination of cross-impact analysis and visualization methods. One of the advantages of the presented method is its simplicity. In most of the scenario-planning methods that exist in the literature, after designing the scenarios, scenario reduction is necessary, while in this study, the most important scenarios can be selected without these problems. In addition, as mentioned in the previous section, in the robust optimization model there is a need to have the probability of scenarios, which the values are determined by the presented scenario-planning method.

In the following, the presented method is applied to design the diesel and biodiesel scenarios of Iran. These scenarios are designed based on the combination of various biodiesel production and diesel consumption trends in Iran. Among the various trends of these parameters, the most important trends are selected according to the news, researches of this field, and experts' opinions (Table 1).

The Delphi method is used to determine and integrate experts' opinions for obtaining the cross-impact matrix (Table 2). The values are between -2 and +2 . Positive values indicate the beneficial impact of trends on each other.

Using Eq. 60, the probability matrix is obtained (Table 3).
$P=0.5+\frac{(0.5 \times \text { SENS } \times \mathrm{CI})}{2}$,

where $\mathrm{CI}$ is the value of the cross-impact matrix and SENS is the sensitivity coefficient that on average is 0.75 .

According to Table 3, the cells T1T5, T1T6, T2T4, and T3T4 have the highest probability values. In fact, the probability of occurrence of these trend combinations is more than that of others. The perspectives of these combined trends form the initial structure of the scenarios. Table 4 shows the result of this method to attain the initial structure of the scenarios. Based on the assumptions and the combined trends, the scenarios are designed and are presented in the following.

\section{Government supports}

Biodiesel production costs have been high in the country. This has led to a high price for these fuels compared to other fossil fuels that are subsidized to a large extent. It is assumed that in this scenario the government supports the private sector to develop biodiesel production. Among these supports are lending to them, guarantee to purchase the generated electricity, and so on.

Moreover, the prices of fossil fuels that were heavily subsidized formerly have been increased and are close to their actual prices. Therefore, the private sector's incentive to invest in this field is increased and, as a result, the biodiesel production will be increased.

A large amount of diesel consumption in recent years has been related to the smuggling of these fuels. In this scenario,

Table 1 Assumptions and trends of biodiesel production and diesel consumption in Iran

\begin{tabular}{lll}
\hline Assumptions & ID & Trends \\
\hline Biodiesel production will increase & T1 & Government support for developing biodiesel production; actualizing the price of fuels \\
Biodiesel production will stay fixed & T2 & Focus on fossil fuels, including petrodiesel \\
Biodiesel production will decrease & T3 & Unwillingness of the people to use biodiesel \\
Diesel consumption will increase & T4 & Unsuccessful implementation of the targeted subsidy plan \\
Diesel consumption will stay fixed & T5 & Applying an incremental tariff system; fuel rationing to prevent smuggling \\
Diesel consumption will decrease & T6 & Changing consumption pattern by increasing culture and awareness of people; phasing \\
& & out old diesel vehicles and using standard vehicles \\
\hline
\end{tabular}

Table 2 Cross-impact matrix

\begin{tabular}{lllllll}
\hline & $\mathrm{T} 1$ & $\mathrm{~T} 2$ & $\mathrm{~T} 3$ & $\mathrm{~T} 4$ & $\mathrm{~T} 5$ & $\mathrm{~T} 6$ \\
\hline $\mathrm{T} 1$ & - & -1.3 & -0.8 & -1.38 & 1.23 & 1.55 \\
$\mathrm{~T} 2$ & & - & 1.03 & 1.32 & 0.73 & -0.63 \\
T3 & & & - & 1.12 & -0.33 & -1.1 \\
T4 & & & & - & -0.47 & -1.23 \\
T5 & & & & & - & 1.03 \\
T6 & & & & & & - \\
\hline
\end{tabular}


Table 3 Probability matrix

\begin{tabular}{|c|c|c|c|c|c|c|}
\hline & $\mathrm{T} 1$ & $\mathrm{~T} 2$ & T3 & T4 & T5 & T6 \\
\hline $\mathrm{T} 1$ & - & 0.256 & 0.35 & 0.241 & 0.731 & 0.791 \\
\hline $\mathrm{T} 2$ & & - & 0.694 & 0.747 & 0.638 & 0.381 \\
\hline $\mathrm{T} 3$ & & & - & 0.709 & 0.438 & 0.294 \\
\hline $\mathrm{T} 4$ & & & & - & 0.413 & 0.269 \\
\hline T5 & & & & & - & 0.694 \\
\hline T6 & & & & & & - \\
\hline
\end{tabular}

Table 4 Results of the method for attaining the scenarios framework

\begin{tabular}{llll}
\hline Scenario & $\begin{array}{l}\text { State of biodiesel } \\
\text { production }\end{array}$ & $\begin{array}{l}\text { State of diesel } \\
\text { consumption }\end{array}$ & $\begin{array}{l}\text { Combination of trends with } \\
\text { high probability of occur- } \\
\text { rence }\end{array}$ \\
\hline Government support & High & Constant & T1T5 \\
Sustainable energy & High & Low & T1T6 \\
Profusion & Constant & High & T2T4 \\
Unwillingness of consumers & Low & High & T3T4 \\
\hline
\end{tabular}

by providing smart fuel cards and fuel rationing, the government has been able to largely prevent the release of this volume of oil products from the country and the loss of national capital. In addition, since a particular stratum of society consumes inefficiently, the government uses an incremental tariff system to improve the pricing of this fuel, so that these groups will pay higher charges for high consumption.

By these actions, the consumption of diesel has been largely reduced and has remained almost constant.

\section{Sustainable energy}

The costs of establishing biorefineries have been much higher compared to returning capital through the purchase of clean electricity by the Ministry of Energy. In this scenario, the government provides more incentives for the private sector by adopting supportive policies, including determining the appropriate price for purchasing clean electricity from biorefineries and providing the possibility of selling by-products.

In addition, by actualizing the price of fuels, there is a fair contest between biodiesel and other fossil fuels, including petrodiesel, which will increase the biodiesel production. In this scenario, fuel prices have been increased and are close to their actual prices.

Since people must pay very high charges for fuel consumption, many changes have been made in their consumption pattern. Old diesel vehicles have been phased out. They also attempt to use standard vehicles, which have less diesel consumption.

With these measures, the consumption of diesel is decreased.
This is the ideal scenario that can be imagined for the country. As diesel consumption decreases and biodiesel production increases, the produced diesel can be exported to increase Iran's international position. In addition, in this scenario, part of the air pollution problems in the big cities will be reduced.

\section{Profusion}

The low price of petrodiesel, which is the result of the unsuccessful implementation of the targeted subsidy plan, has prevented people from worrying about its consumption. Therefore, these fuels are consumed profusely. Such profuse behavior exists in many of the energy sectors, including transport, industry, agriculture, and so on, which will further increase the country's diesel consumption. Low petrodiesel prices reduced the willingness of the private sector to invest in the field of biodiesel production.

According to the presence of abundant fossil resources and the delivery of cheap fossil fuels to power plants and the transportation system, in this scenario, supporting renewable energy production, including biodiesel, is not a priority for the country regarding energy supplies.

Therefore, the government does not pay much attention to the development of biodiesel production and its focus is on fossil fuels, including petrodiesel, and as a result biodiesel production has remained almost constant.

\section{Unwillingness of the consumers}

It is assumed that in this scenario, the targeted subsidy plan is not well implemented, and many subsidies are still paid for petrodiesel. Therefore, the culture of saving and 
optimizing energy consumption has not been established in the country, and as a result diesel consumption continues to increase.

In addition, because biodiesel production costs are high and its price is low compared to the price of subsidized petrodiesel, the private sector has no interest to invest in biodiesel production.

In this scenario, people are reluctant to use biodiesel. One of the main reasons for this is the higher cost of this fuel than other fossil fuels, including petrodiesel. In addition, because people are not aware of the importance and benefits of this fuel, they are not very interested in using this new fuel.

Consequently, there is no incentive to produce biodiesel that its production will reduce.

This is the worst possible scenario. By increasing diesel consumption and reducing biodiesel production, environmental problems such as air pollution will be aggravated. In addition, it can no longer be possible to export diesel, and if this trend continues Iran will become a diesel importer.

\section{Estimation of uncertain parameters}

As stated in "Data gathering", the current values of each of the parameters were extracted from the relevant references. In this research, a 7-year (periods) planning horizon is considered. To solve the proposed mathematical programming (robust optimization) model, it is necessary to estimate the values of the uncertain parameters for each of the periods. Predictive methods focus only on the most likely event and lead to a point estimate of the future and ignore the uncertainties, while scenario planning is a powerful tool that considers uncertainties and possible future occurrences.

Therefore, in this study, a scenario-planning method is presented for estimating the uncertain parameters. In the proposed supply chain model, biodiesel demand, supply of WCO, costs (fixed, variable, production, inventory holding, and transportation costs), and environmental impacts have uncertain nature. These parameters are estimated so that their values will change by a percentage in each period, based on the structure of each scenario (the conditions that may occur in the future), which are shown in Table 5. These values are obtained according to the structure of the designed scenarios and based on experts' opinions (with Delphi method).

For example, as mentioned in the previous section in the description of "sustainable energy" scenario, in this scenario, there is the highest biodiesel demand, the highest biodiesel production, the lowest air pollution, and the lowest costs in comparison to other scenarios. Similarly, these values are estimated for other scenarios (shown in Table 5).

\section{Results and discussions}

In this study, a scenario-based robust optimization model is proposed for designing a biodiesel supply chain network. In this section, the results of solving the proposed model will be discussed. This model determines the optimal number, location, and capacity of the facilities (Jatropha cultivation sites, Norouzak cultivation sites, oil extraction sites, refineries, and distribution sites) over the planning horizon.

The proposed supply chain and the developed mathematical programming model are based on the specific characteristics of Iran. For example, non-edible sources including Jatropha and Norouzak which are compatible with the climate of Iran, are considered as biodiesel production sources. The most suitable places for cultivating these plants are selected as the candidate locations, with 11 locations for cultivating Jatropha, and 7 locations for cultivating Norouzak being considered. The other suitable source for producing biodiesel in the country is WCO, in which 30 locations for supplying this source are selected. Similarly, 30 locations for extracting oil, 9 locations for refineries, 30 locations for distributing, and 7 locations for consumer centers are considered. In addition, the time period of 7 years and two transportation modes are taken into account. Hence, the size of the proposed network is $11 \times 7 \times 30 \times 30 \times 9 \times 30 \times 7 \times 2 \times 7$.

GAMS software and its CPLEX solver are used to solve this model. The optimum solution is obtained after $25 \mathrm{~min}$. Since strategic decisions are taken by the proposed model, this solving time is reasonable.

The optimal value of the objective function and its components are summarized in Table 6. As shown in Table 6, all components have high share in total costs; however, the maximum cost is related to variable opening costs.

The optimal number, location, and capacity of the facilities which are determined by the model will be stated in the following. It is worth noting that, due to budget limitations, some upper bounds for the capacity of facilities are considered. In addition, for considering the advantage of economy of scale, some lower bounds are applied. Therefore, these capacities are between their corresponding lower and upper bounds.

Table 5 Changes of the uncertain parameters in each period (\%)

\begin{tabular}{lcclc}
\hline Scenarios & $\begin{array}{l}\text { Sup- } \\
\text { ply of } \\
\text { WCO }\end{array}$ & Costs & $\begin{array}{l}\text { Environ- } \\
\text { mental } \\
\text { impacts }\end{array}$ & $\begin{array}{l}\text { Biodiesel } \\
\text { demand }\end{array}$ \\
\hline Government support & 2 & 0.6 & -0.3 & 2 \\
Sustainable energy & 3 & 0.3 & -1 & 3 \\
Profusion & 0 & 1.5 & 0.5 & 0 \\
$\quad \begin{array}{l}\text { Unwillingness of consum- } \\
\quad\end{array}$ & -1 & 3 & 1.2 & -1 \\
\hline
\end{tabular}


Table 6 The share of different costs in the objective function (million Iranian rials)

\begin{tabular}{llllll}
\hline Fixed opening cost & Variable opening cost & Production cost & Inventory holding cost & Transportation cost & Total \\
\hline 1372676.238 & $1.235663 \mathrm{E}+9$ & $4.668789 \mathrm{E}+8$ & $1.495950 \mathrm{E}+07$ & $8.184992 \mathrm{E}+7$ & $1.800724 \mathrm{E}+9$ \\
\hline
\end{tabular}

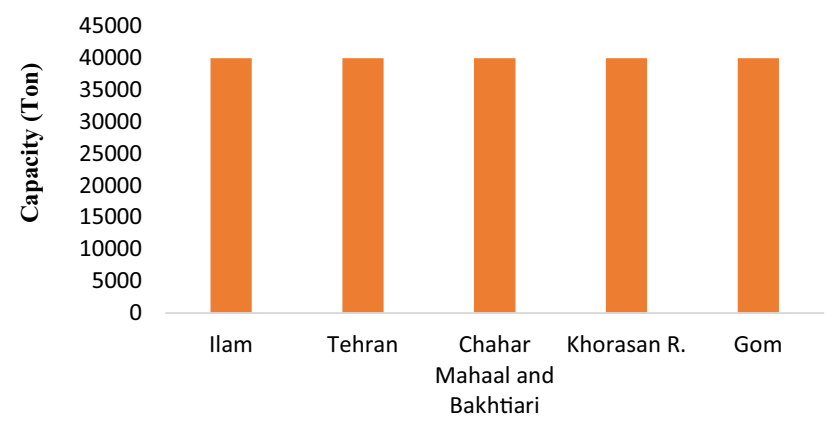

Fig. 3 Optimal locations for cultivating Jatropha

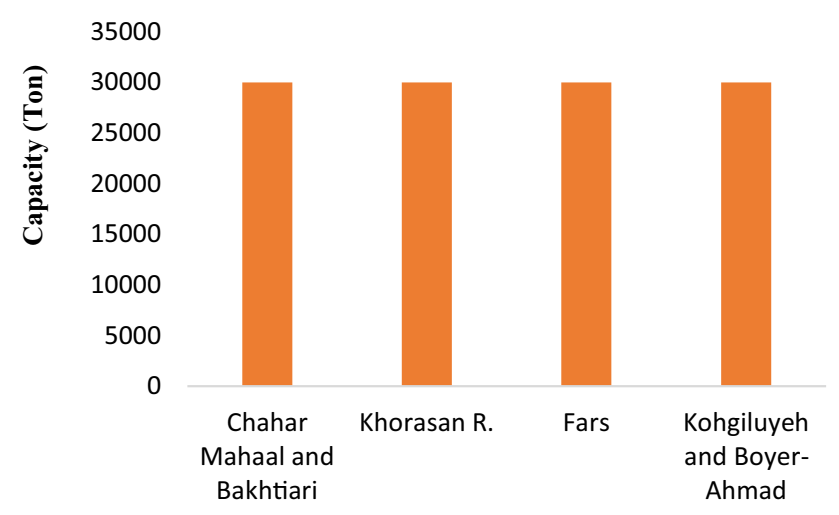

Fig. 4 Optimal locations for cultivating Norouzak

The best locations for cultivating Jatropha and Norouzak are shown in Figs. 3 and 4, respectively. These figures show that it is necessary to cultivate more Jatropha than Norouzak for biodiesel production. In addition, these two figures indicate that in each of the selected cities, equal capacities for cultivation of Jatropha and Norouzak are determined by solving the model.

The optimal locations for establishing oil extraction centers and their capacities are summarized in Table 7 . These values are sum of the initial capacities and the expansion of capacities in each period. As shown in Table 7, oil extraction centers are established in Jatropha and Norouzak cultivation centers. This result can be explained based on reducing transportation costs. Chahar Mahaal and Bakhtiari, Ilam, and Khorasan R. cities have major capacities. Therefore, more attention and funding must be paid to these cities by the decision makers.

The best locations for establishing refineries and their capacities are illustrated in Fig. 5. According to Fig. 5, the capacity of refineries increases almost linearly over the planning horizon.

Figure 6 shows the location and capacity of established distribution centers. The total capacities of distribution centers are the sum of their initial capacities and their expansions in each period. To reduce transportation costs, distribution centers are established in refinery centers and some of their surrounding provinces. As shown in Fig. 6, Isfahan and Kerman have the highest and lowest capacities, respectively.

The summary of the best locations for cultivation of Jatropha and Norouzak, oil extraction sites, refineries, and distribution sites are shown in Fig. 7. As shown in Fig. 7, the number of distribution sites is more than the other facilities. This can be justified based on reducing transportation costs, i.e., the model prefers to establish more distribution sites for reducing transportation costs. In addition to the reduction of transportation costs, when the number of established facilities is increased, the disruption risks will be reduced. However, in this condition, the fixed and variable opening costs may be increased.

Table 7 Optimal locations and capacities of oil extraction centers

\begin{tabular}{|c|c|c|c|c|c|c|c|}
\hline \multirow[t]{2}{*}{ City } & \multicolumn{7}{|l|}{ Years } \\
\hline & 1 & 2 & 3 & 4 & 5 & 6 & 7 \\
\hline Ilam & 20,000 & 60,000 & 180,000 & 340,000 & 540,000 & 740,000 & 940,000 \\
\hline Tehran & 20,000 & 60,000 & 120,000 & 160,000 & 200,000 & 400,000 & 600,000 \\
\hline Chahar Mahaal and Bakhtiari & 251,000 & 291,000 & 351,000 & 391,000 & 431,000 & 741,843 & $1,172,843$ \\
\hline Khorasan R. & 251,000 & 291,000 & 351,000 & 391,000 & 431,000 & 431,000 & 841,088 \\
\hline Fars & 231,000 & 231,000 & 231,000 & 231,000 & 231,000 & 231,000 & 462,000 \\
\hline Gom & 20,000 & 60,000 & 120,000 & 160,000 & 360,000 & 560,000 & 760,000 \\
\hline Kohgiluyeh and Boyer-Ahmad & 231,000 & 231,000 & 231,000 & 231,000 & 231,000 & 231,000 & 462,000 \\
\hline Total & $1,024,000$ & $1,224,000$ & $1,584,000$ & $1,904,000$ & $2,424,000$ & $3,334,843$ & $5,237,930$ \\
\hline
\end{tabular}


Fig. 5 Optimal locations and capacities of refineries in the time period

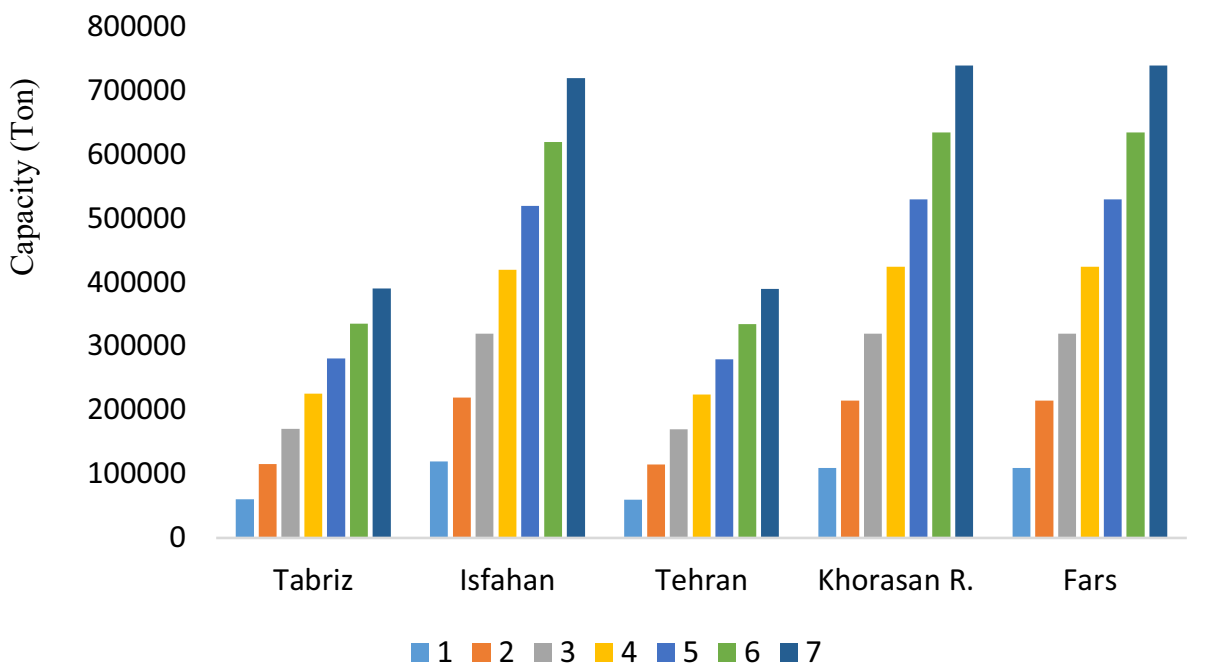

There are some air pollution problems in the country, especially in big cities. Therefore, in this study, the environmental impacts of all the processes of the proposed supply chain are also considered. This issue is addressed by a constraint in the mathematical programming model so that the amount of $\mathrm{CO}_{2}$ emissions from the processes through the constructed supply chain must not exceed the considered upper bound. Total $\mathrm{CO}_{2}$ emissions in each of the scenarios are shown in Fig. 8. As shown in Fig. 8, "sustainable energy" and "unwillingness of the consumers" scenarios have the lowest and the highest $\mathrm{CO}_{2}$ emissions, respectively. These results are in accordance with the structure of the designed scenarios.

The results of this study show the effectiveness of the presented approach in designing the biodiesel supply chain network. Presenting a mathematical programming model based on the specific characteristics of the country will greatly improve its performance. The results can help energy planners, policy makers, private industry, and others for taking appropriate strategic decisions about the biodiesel supply chain network, considering the uncertainties in the model makes it closer to the real world. Predictive methods focus only on the most likely event, while scenario planning is a powerful tool that considers uncertainties and possible future occurrences. Therefore, estimation of the parameters by the presented scenario-planning method gives the government, organizations, and decision makers the ability to worry less about future events and uncertainties. Furthermore, considering environmental constraint in the model can help in reducing air pollution problems in the industrial and big cities of Iran. In addition to the advantage of reducing air pollution problem, the development of these biofuels brings the opportunity for exporting of fossil fuels to increase Iran's geopolitical position in the region.
Fig. 6 Optimal locations and capacities of distribution centers in the time period

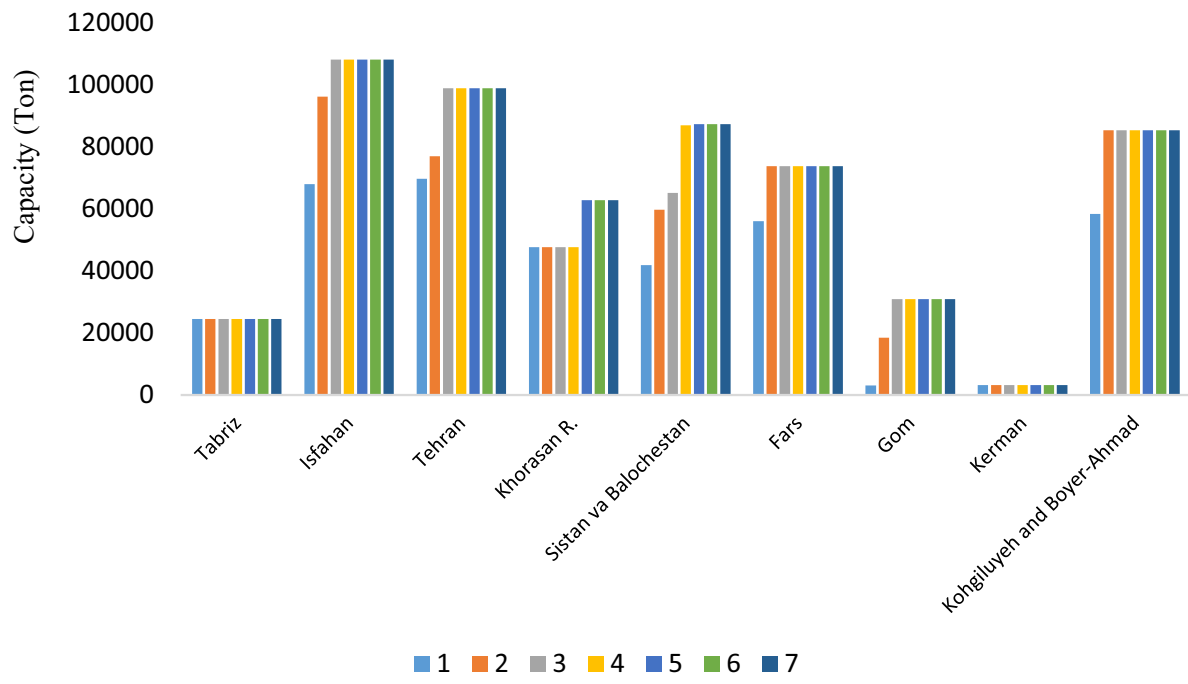

Springer 


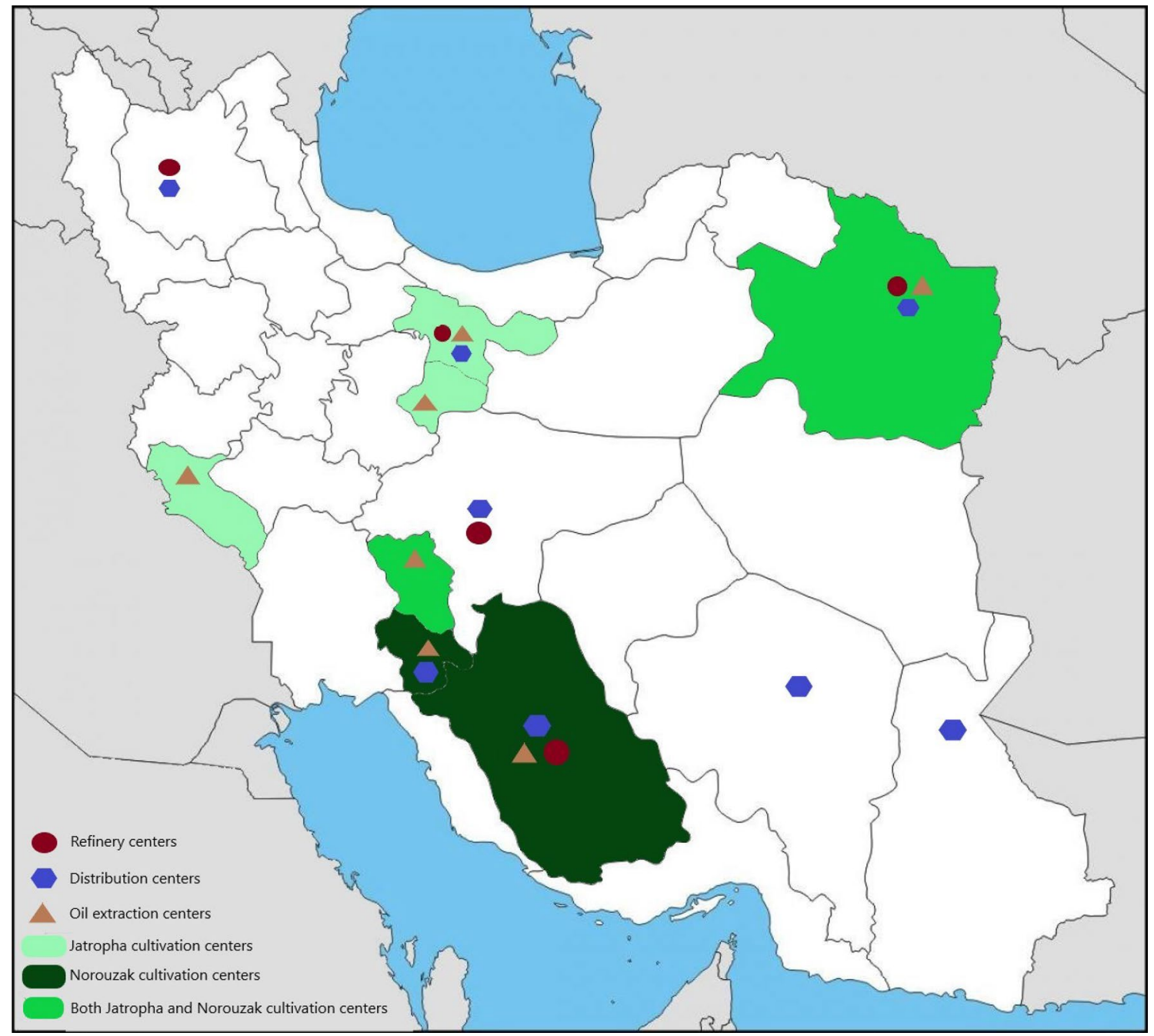

Fig. 7 The best locations for establishing the facilities

$6.00 \mathrm{E}+11$$$
\begin{aligned}
& \text { 00 } \\
& 0 \\
& 0 \\
& 0 \\
& 0 \\
& 0 \\
& .0 \\
& 0 \\
& 0 \\
& 0 \\
& 0 \\
& \frac{0}{0} \\
& 0 \\
& 0
\end{aligned}
$$

$5.00 \mathrm{E}+11$

4.00E+11

$3.00 \mathrm{E}+11$

$2.00 \mathrm{E}+11$

$1.00 \mathrm{E}+11$

$0.00 \mathrm{E}+00$

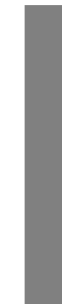

Government Sustainable supports

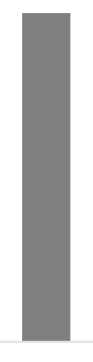

Profusion Unwillingness consumers

Fig. 8 Total $\mathrm{CO}_{2}$ emissions in each of the scenarios

\section{Conclusion}

The most important challenge for developing biodiesel is its high production cost, which by optimally designing the supply chain network will be reduced. In this paper, a scenariobased robust optimization model is proposed to design a biodiesel supply chain network under uncertainty. Non-edible sources including Jatropha, Norouzak, and WCO are used as sources of biodiesel production. In addition, in this study, an environmental constraint is considered, in that the amount of $\mathrm{CO}_{2}$ emissions from the processes through the constructed supply chain must not exceed the considered upper bound.

In the proposed supply chain, some parameters including biodiesel demand, supply of WCO, costs, and environmental 
impact parameters have uncertain nature. In this study, a scenario-planning approach which is a combination of crossimpact analysis and visualization methods is proposed to determine the probability of scenarios and to estimate the values of the uncertain parameters under each scenario. The proposed model tries to optimize average condition of scenarios subject to reach feasibility for all scenarios. The presented model is implemented in a real case study in Iran for a 7-year planning horizon. This model determines the number, location, and capacity of facilities with the goal of minimizing the total cost.

Open Access This article is distributed under the terms of the Creative Commons Attribution 4.0 International License (http://creativeco mmons.org/licenses/by/4.0/), which permits unrestricted use, distribution, and reproduction in any medium, provided you give appropriate credit to the original author(s) and the source, provide a link to the Creative Commons license, and indicate if changes were made.

\section{Appendix: Nomenclature}

\begin{tabular}{|c|c|}
\hline \multicolumn{2}{|l|}{ Sets } \\
\hline$j$ & Possible locations for cultivating Jatropha \\
\hline$n$ & Possible locations for cultivating Norouzak \\
\hline$w$ & Possible locations for WCO supply sites \\
\hline$e$ & Possible locations for oil extraction sites \\
\hline$r$ & Possible locations for refineries \\
\hline$k$ & Possible locations for distribution sites \\
\hline$u$ & Biodiesel consumer centers \\
\hline$l$ & Transport modes \\
\hline$o$ & Capacity options for refineries \\
\hline$t$ & Time period \\
\hline$s$ & Scenarios \\
\hline \multicolumn{2}{|c|}{ Technical parameters } \\
\hline $\mathrm{DB}_{u t s}$ & $\begin{array}{l}\text { Demand for biodiesel at consumer center } u \text { at period } t \\
\text { under scenario } s\end{array}$ \\
\hline $\mathrm{WS}_{w t s}$ & $\begin{array}{l}\text { Quantity of WCO supplied by supply site } w \text { at period } t \\
\text { under scenario } s\end{array}$ \\
\hline$L_{j}^{1}$ & Minimum Jatropha cultivation area in location $j$ \\
\hline$U_{j}^{1}$ & Maximum Jatropha cultivation area in location $j$ \\
\hline$L_{n}^{2}$ & Minimum Norouzak cultivation area in location $n$ \\
\hline$U_{n}^{2}$ & Maximum Norouzak cultivation area in location $n$ \\
\hline$L_{e}^{3}$ & Minimum capacity of oil extraction site $e$ \\
\hline$U_{e}^{3}$ & Maximum capacity of oil extraction site $e$ \\
\hline$L_{r}^{4}$ & Minimum capacity of refinery $r$ \\
\hline$U_{r}^{4}$ & Maximum capacity of refinery $r$ \\
\hline$L_{k}^{5}$ & Minimum capacity of distribution site $k$ \\
\hline$U_{k}^{5}$ & Maximum capacity of distribution site $k$ \\
\hline $\mathrm{MN}^{1}$ & $\begin{array}{l}\text { Minimum number of locations that must be consid- } \\
\text { ered for cultivating Jatropha }\end{array}$ \\
\hline $\mathrm{MN}^{2}$ & $\begin{array}{l}\text { Minimum number of locations that must be consid- } \\
\text { ered for cultivating Norouzak }\end{array}$ \\
\hline
\end{tabular}

$\mathrm{MX}^{1} \quad$ Maximum number of locations that can be considered for opening oil extraction centers

$\mathrm{MX}^{2} \quad$ Maximum number of locations that can be considered for opening refineries

$\mathrm{MX}^{3} \quad$ Maximum number of locations that can be considered for opening distribution centers

$\alpha_{j t}^{1} \quad$ Quantity of Jatropha yields per hectare in site $j$ at period $t$

$\alpha^{2} \quad$ Quantity of Norouzak yields per hectare

$\beta^{1} \quad$ Conversion rate of Jatropha to Jatropha oil

$\beta^{2} \quad$ Conversion rate of Norouzak to Norouzak oil

$\beta^{3} \quad$ Conversion rate of WCO to pretreated WCO

$\varphi^{1} \quad$ Conversion rate of Jatropha oil to biodiesel

$\varphi^{2} \quad$ Conversion rate of Norouzak oil to biodiesel

$\varphi^{3} \quad$ Conversion rate of pretreated WCO to biodiesel

$\mathrm{FW}_{r t} \quad$ Initial capacity of refinery $r$ at period $t$

$\mathrm{CW}_{\text {ort }} \quad$ Capacity of option $o$ for refinery $r$ at period $t$

$\mathrm{PR}_{s} \quad$ Probability of scenario $s$

Cost parameters

$\mathrm{FC}_{j s}^{1} \quad$ Fixed cost of cultivating Jatropha in site $j$ under scenario $s$

$\mathrm{FC}_{n s}^{2} \quad$ Fixed cost of cultivating Norouzak in site $n$ under scenario $s$

$\mathrm{FC}_{e s}^{3} \quad$ Fixed cost of establishing oil extraction site $e$ at period $t$ under scenario $s$

$\mathrm{FC}_{r s}^{4} \quad$ Fixed cost of establishing refinery $r$ under scenario $s$

$\mathrm{FC}_{k s}^{5} \quad$ Fixed cost of establishing distribution site $k$ under scenario $s$

$\mathrm{FO}_{\text {orts }} \quad$ Fixed cost of adding capacity option $o$ to refinery $r$ at period $t$ under scenario $s$

$\mathrm{VC}_{j s}^{1} \quad$ Variable unit cost of cultivating Jatropha in site $j$ under scenario $s$

$\mathrm{VC}_{n s}^{2}$

$\mathrm{VC}_{e t s}^{3}$

$\mathrm{VC}_{r t s}^{4}$

$\mathrm{VC}_{k t s}^{5}$

$\mathrm{PC}_{j t s}^{1}$

$\mathrm{PC}_{n t s}^{2}$

$\mathrm{PC}_{w t s}^{3}$

$\mathrm{PC}_{e t s}^{4}$

$\mathrm{PC}_{e t s}^{5}$

$\mathrm{PC}_{r t s}^{6}$

$\mathrm{PC}_{r t s}^{7}$

$\mathrm{IC}_{\text {ets }}^{1}$

Variable unit cost of cultivating Norouzak in site $n$ under scenario $s$

Variable unit cost of oil extraction site $e$ at period $t$ under scenario $s$

Variable unit cost of refinery $r$ at period $t$ under scenario $s$

Variable unit cost of establishing distribution site $k$ at period $t$ under scenario $s$

Production cost per unit of Jatropha in Jatropha cultivation site $j$ at period $t$ under scenario $s$

Production cost per unit of Norouzak in Norouzak cultivation site $n$ at period $t$ under scenario $s$

Collection cost per unit of WCO in supply site $w$ at period $t$ under scenario $s$

Production cost per unit of Jatropha oil in oil extraction site $e$ at period $t$ under scenario $s$

Production cost per unit of Norouzak oil in oil extraction site $e$ at period $t$ under scenario $s$

Production cost per unit of pretreated WCO in refinery $r$ at period $t$ under scenario $s$

Production cost per unit of biodiesel in refinery $r$ at period $t$ under scenario $s$

Inventory holding unit cost of Jatropha in oil extraction site $e$ at period $t$ under scenario $s$ 


\begin{tabular}{|c|c|c|c|}
\hline $\mathrm{IC}_{e t s}^{2}$ & $\begin{array}{l}\text { Inventory holding unit cost of Norouzak in oil extrac- } \\
\text { tion site } e \text { at period } t \text { under scenario } s \\
\text { Inventory holding unit cost of biodiesel in refinery } r \text { at }\end{array}$ & $\mathrm{ET}_{\text {elrs }}^{5}$ & $\begin{array}{l}\text { Environmental effect of transporting per unit of } \\
\text { Norouzak oil from oil extraction site } e \text { to refinery } r \\
\text { using mode } l \text { under scenario } s\end{array}$ \\
\hline $\mathrm{IC}_{r t s}^{3}$ & $\begin{array}{l}\text { Inventory holding unit cost of biodiesel in refinery } r \text { at } \\
\text { period } t \text { under scenario } s\end{array}$ & \multirow[t]{2}{*}{$\mathrm{ET}_{r l k s}^{6}$} & \multirow{2}{*}{$\begin{array}{l}\text { Environmental effect of transporting per unit of } \\
\text { biodiesel from refinery } r \text { to distribution site } k \text { using } \\
\text { mode } l \text { under scenario } s\end{array}$} \\
\hline $\mathrm{IC}_{k t s}^{4}$ & $\begin{array}{l}\text { Inventory holding unit cost of biodiesel in distribution } \\
\text { site } k \text { at period } t \text { under scenario } s\end{array}$ & & \\
\hline $\mathrm{TC}_{j l e t s}^{1}$ & $\begin{array}{l}\text { Per unit transportation cost of Jatropha from Jatropha } \\
\text { cultivation site } j \text { to oil extraction site } e \text { using mode } l \\
\text { at period } t \text { under scenario } s\end{array}$ & $\mathrm{ET}_{k l u s}^{7}$ & $\begin{array}{l}\text { Environmental effect of transporting per unit of bio- } \\
\text { diesel from distribution site } k \text { to consumer center } u \\
\text { using mode } l \text { under scenario } s\end{array}$ \\
\hline \multirow[t]{2}{*}{$\mathrm{TC}_{\text {nlets }}^{2}$} & \multirow{2}{*}{$\begin{array}{l}\text { Per unit transportation cost of Norouzak from Norou- } \\
\text { zak cultivation site } n \text { to oil extraction site } e \text { using } \\
\text { mode } l \text { at period } t \text { under scenario } s\end{array}$} & $\mathrm{EI}_{s}^{1}$ & $\begin{array}{l}\text { Environmental effect of inventory holding per unit of } \\
\text { Jatropha in oil extraction sites under scenario } s\end{array}$ \\
\hline & & $\mathrm{EI}_{s}^{2}$ & Environmental effect of inventory holding per unit of \\
\hline \multirow{2}{*}{$\mathrm{TC}_{\text {wlrts }}^{3}$} & \multirow{2}{*}{$\begin{array}{l}\text { Per unit transportation cost of WCO from supply } \\
\text { site } w \text { to refinery } r \text { using mode } l \text { at period } t \text { under } \\
\text { scenario } s\end{array}$} & & traction sites under scenario $s$ \\
\hline & & $\mathrm{EI}_{s}^{3}$ & $\begin{array}{l}\text { Environmental effect of inventory holding per unit of } \\
\text { biodiesel in refineries under scenario } s\end{array}$ \\
\hline $\mathrm{TC}_{\text {elrts }}^{4}$ & \multirow{2}{*}{$\begin{array}{l}\text { Per unit transportation cost of Jatropha oil from oil } \\
\text { extraction site } e \text { to refinery } r \text { using mode } l \text { at period } t \\
\text { under scenario } s\end{array}$} & $\mathrm{EI}_{s}^{4}$ & $\begin{array}{l}\text { Environmental effect of inventory holding per unit of } \\
\text { biodiesel in distribution sites under scenario } s\end{array}$ \\
\hline \multirow{2}{*}{$\mathrm{TC}_{\text {elrts }}^{5}$} & & $D_{j l e}^{1}$ & $\begin{array}{l}\text { Distance between Jatropha cultivation site } j \text { and oil } \\
\text { extraction site } e \text { using mode } l\end{array}$ \\
\hline & $\begin{array}{l}\text { Per unit transportation cost of Norouzak oil from oil } \\
\text { extraction site } e \text { to refinery } r \text { using mode } l \text { at period } t \\
\text { under scenario } s\end{array}$ & $D_{n l e}^{2}$ & $\begin{array}{l}\text { Distance between Norouzak cultivation site } n \text { and oil } \\
\text { extraction site } e \text { using mode } l\end{array}$ \\
\hline $\mathrm{TC}_{r l k t s}^{6}$ & $\begin{array}{l}\text { Per unit transportation cost of biodiesel from refinery } \\
r \text { to distribution site } k \text { using mode } l \text { at period } t \text { under } \\
\text { scenario } s\end{array}$ & $D_{w l r}^{3}$ & $\begin{array}{l}\text { Distance between supply site } w \text { and refinery } r \text { using } \\
\text { mode } l\end{array}$ \\
\hline \multirow[t]{2}{*}{$\mathrm{TC}_{k l u t s}^{7}$} & \multirow{2}{*}{$\begin{array}{l}\text { Per unit transportation cost of biodiesel from distribu- } \\
\text { tion site } k \text { to consumer center } u \text { using mode } l \text { at } \\
\text { period } t \text { under scenario } s\end{array}$} & $D_{e l r}^{4}$ & $\begin{array}{l}\text { Distance between oil extraction site } e \text { and refinery } r \\
\text { using mode } l\end{array}$ \\
\hline & & $D_{r l k}^{5}$ & $\begin{array}{l}\text { Distance between refinery } r \text { and distribution site } k \\
\text { using mode } l\end{array}$ \\
\hline \multicolumn{2}{|c|}{ Environmental impact parameters } & $D_{k+l}^{6}$ & Distance between distribution site $k$ and consumer \\
\hline MGW & $\begin{array}{l}\text { Maximum permitted global warming potential by the } \\
\text { supply chain }\end{array}$ & Binary & center $u$ using mode $l$ \\
\hline $\mathrm{EC}_{s}^{1}$ & $\begin{array}{l}\text { Environmental effect of harvesting per unit of Jatropha } \\
\text { under scenario } s\end{array}$ & $v_{j}^{1}$ & $\begin{array}{l}1 \text { if a Jatropha cultivation center is selected in location } \\
j ; 0 \text { otherwise }\end{array}$ \\
\hline $\mathrm{EC}_{s}^{2}$ & $\begin{array}{l}\text { Environmental effect of harvesting per unit of Norou- } \\
\text { zak under scenario } s\end{array}$ & $v_{n}^{2}$ & $\begin{array}{l}1 \text { if a Norouzak cultivation center is selected in loca- } \\
\text { tion } n ; 0 \text { otherwise }\end{array}$ \\
\hline $\mathrm{EC}_{s}^{3}$ & $\begin{array}{l}\text { Environmental effect of establishing per unit capacity } \\
\text { of oil extraction sites under scenario } s\end{array}$ & $v_{e}^{3}$ & $\begin{array}{l}1 \text { if an oil extraction center is established in location } e \\
0 \text { otherwise }\end{array}$ \\
\hline $\mathrm{EC}_{s}^{4}$ & $\begin{array}{l}\text { Environmental effect of establishing per unit capacity } \\
\text { of refineries under scenario } s\end{array}$ & $v_{r t}^{4}$ & $\begin{array}{l}1 \text { if a refinery is established in location } r \text { at period } t ; 0 \\
\text { otherwise }\end{array}$ \\
\hline $\mathrm{EC}_{s}^{5}$ & $\begin{array}{l}\text { Environmental effect of establishing per unit capacity } \\
\text { of distribution sites under scenario } s\end{array}$ & $v_{k}^{5}$ & $\begin{array}{l}1 \text { if a distribution center is established in location } k ; 0 \\
\text { otherwise }\end{array}$ \\
\hline $\mathrm{EP}_{s}^{1}$ & $\begin{array}{l}\text { Environmental effect of producing per unit of Jatropha } \\
\text { oil in oil extraction sites under scenario } s\end{array}$ & $z_{\text {ort }}$ & $\begin{array}{l}1 \text { if capacity option } o \text { is added to refinery } r \text { at period } t \text {; } \\
0 \text { otherwise }\end{array}$ \\
\hline $\mathrm{EP}_{s}^{2}$ & $\begin{array}{l}\text { Environmental effect of producing per unit of Norou- } \\
\text { zak oil in oil extraction sites under scenario } s\end{array}$ & Cont & ecision variables \\
\hline $\mathrm{EP}_{s}^{3}$ & $\begin{array}{l}\text { Environmental effect of producing per unit of bio- } \\
\text { diesel in refineries under scenario } s\end{array}$ & $h_{\text {ets }}^{1}$ & $\begin{array}{l}\text { Inventory amount of Jatropha in oil extraction site } e \text { at } \\
\text { period } t \text { under scenario } s\end{array}$ \\
\hline $\mathrm{ET}_{j l e s}^{1}$ & $\begin{array}{l}\text { Environmental effect of transporting per unit of } \\
\text { Jatropha from Jatropha cultivation site } j \text { to oil extrac- }\end{array}$ & $h_{e t s}^{2}$ & $\begin{array}{l}\text { Inventory amount of Norouzak in oil extraction site } e \\
\text { at period } t \text { under scenario } s\end{array}$ \\
\hline & & $h_{r t s}^{3}$ & $\begin{array}{l}\text { Inventory amount of biodiesel in refinery } r \text { at period } t \\
\text { under scenario } s\end{array}$ \\
\hline $\mathrm{ET}_{\text {nles }}^{2}$ & $\begin{array}{l}\text { Environmental effect of transporting per unit of } \\
\text { Norouzak from Norouzak cultivation site } n \text { to oil } \\
\text { extraction site } e \text { using mode } l \text { under scenario } s\end{array}$ & $h_{k t s}^{4}$ & $\begin{array}{l}\text { Inventory amount of biodiesel in distribution site } k \text { at } \\
\text { period } t \text { under scenario } s\end{array}$ \\
\hline $\mathrm{ET}_{w l r s}^{3}$ & $\begin{array}{l}\text { Environmental effect of transporting per unit of WCO } \\
\text { from supply site } w \text { to refinery } r \text { using mode } l \text { under }\end{array}$ & $p_{j t s}^{1}$ & $\begin{array}{l}\text { Amount of Jatropha produced in Jatropha cultivation } \\
\text { site } j \text { at period } t \text { under scenario } s\end{array}$ \\
\hline & & $p_{n t s}^{2}$ & $\begin{array}{l}\text { Amount of Norouzak produced in Norouzak cultiva- } \\
\text { tion site } n \text { at period } t \text { under scenario } s\end{array}$ \\
\hline $\mathrm{ET}_{\text {elrs }}^{4}$ & $\begin{array}{l}\text { Environmental effect of transporting per unit of Jat- } \\
\text { ropha oil from oil extraction site } e \text { to refinery } r \text { using } \\
\text { mode } l \text { under scenario } s\end{array}$ & $p_{\text {ets }}^{4}$ & $\begin{array}{l}\text { Amount of Jatropha oil produced in oil extraction site } \\
e \text { at period } t \text { under scenario } s\end{array}$ \\
\hline
\end{tabular}




\begin{tabular}{|c|c|}
\hline$p_{\text {ets }}^{5}$ & $\begin{array}{l}\text { Amount of Norouzak oil produced in oil extraction } \\
\text { site } e \text { at period } t \text { under scenario } s\end{array}$ \\
\hline$p_{r t s}^{6}$ & $\begin{array}{l}\text { Amount of pretreated WCO produced at refinery } r \text { at } \\
\text { period } t \text { under scenario } s\end{array}$ \\
\hline$p_{r t s}^{7}$ & $\begin{array}{l}\text { Amount of biodiesel produced in refinery } r \text { at period } t \\
\text { under scenario } s\end{array}$ \\
\hline$f_{j l e t s}^{1}$ & $\begin{array}{l}\text { Amount of Jatropha transported from Jatropha cultiva- } \\
\text { tion site } j \text { to oil extraction site } e \text { using mode } l \text { at } \\
\text { period } t \text { under scenario } s\end{array}$ \\
\hline$f_{\text {nlets }}^{2}$ & $\begin{array}{l}\text { Amount of Norouzak transported from Norouzak } \\
\text { cultivation site } n \text { to oil extraction site } e \text { using mode } l \\
\text { at period } t \text { under scenario } s\end{array}$ \\
\hline$f_{\text {wlrts }}^{3}$ & $\begin{array}{l}\text { Amount of WCO transported from supply site } w \text { to } \\
\text { refinery } r \text { using mode } l \text { at period } t \text { under scenario } s\end{array}$ \\
\hline$f_{\text {elrts }}^{4}$ & $\begin{array}{l}\text { Amount of Jatropha oil transported from oil extraction } \\
\text { site } e \text { to refinery } r \text { using mode } l \text { at period } t \text { under } \\
\text { scenario } s\end{array}$ \\
\hline$f_{\text {elrts }}^{5}$ & $\begin{array}{l}\text { Amount of Norouzak oil transported from oil extrac- } \\
\text { tion site } e \text { to refinery } r \text { using mode } l \text { at period } t \text { under } \\
\text { scenario } s\end{array}$ \\
\hline$f_{r l k t s}^{6}$ & $\begin{array}{l}\text { Amount of biodiesel transported from refinery } r \text { to } \\
\text { distribution site } k \text { using mode } l \text { at period } t \text { under } \\
\text { scenario } s\end{array}$ \\
\hline$f_{\text {kluts }}^{7}$ & $\begin{array}{l}\text { Amount of biodiesel transported from distribution } \\
\text { site } k \text { to consumer center } u \text { using mode } l \text { at period } t \\
\text { under scenario } s\end{array}$ \\
\hline$q_{j}^{1}$ & Quantity of cultivated area of Jatropha in site $j$ \\
\hline$q_{n}^{2}$ & Quantity of cultivated area of Norouzak in site $n$ \\
\hline$q_{e t}^{3}$ & Capacity of oil extraction site $e$ at period $t$ \\
\hline$q_{r t}^{4}$ & Capacity of refinery $r$ at period $t$ \\
\hline$q_{k t}^{5}$ & Capacity of distribution site $k$ at period $t$ \\
\hline$q e_{e t}^{1}$ & $\begin{array}{l}\text { Quantity of capacity expansion in oil extraction site } e \\
\text { at period } t\end{array}$ \\
\hline$q e_{k t}^{2}$ & $\begin{array}{l}\text { Quantity of capacity expansion in distribution site } k \\
\text { at period } t\end{array}$ \\
\hline
\end{tabular}

\section{References}

1. Asumadu-Sarkodie, S., Owusu, P.A.: A review of Ghana's energy sector national energy statistics and policy framework. Cogent Eng. 3, 1155274 (2016)

2. Lazaroiu, G., Mihaescu, L., Pisa, I., Negreanu, G.-P., Berbece, V.: The role of agricultural biomass in the production of ecological energy in Romania. Int. Multidiscip. Sci. GeoConf. SGEM Surv. Geol. Min. Ecol. Manag. 18, 721-726 (2018)

3. Lazaroiu, G., Mihaescu, L., Negreanu, G., Pana, C., Pisa, I., Cernat, A., Ciupageanu, D.-A.: Experimental investigations of innovative biomass energy harnessing solutions. Energies 11, 3469 (2018)

4. Lăzăroiu, G., Mocanu, R.C., Bondrea, A.D., Mavrodin, E.M., Balanescu, L.: Use of animal fat waste as a bio-fuel. Int. Multidiscip. Sci. GeoConf. SGEM Surv. Geol. Min. Ecol. Manag. 17, 675-682 (2017)

5. Papapostolou, C., Kondili, E., Kaldellis, J.K.: Development and implementation of an optimisation model for biofuels supply chain. Energy 36, 6019-6026 (2011)

6. Martino, J.P.: A review of selected recent advances in technological forecasting. Technol. Forecast. Soc. Change 70, 719-733 (2003)
7. Hajinezhad, A., Abedi, S., Ghobadian, B., Noorollahi, Y.: Biodiesel production from Norouzak (Salvia lerifolia) seeds as an indigenous source of bio fuel in Iran using ultrasound. Energy Convers. Manag. 99, 132-140 (2015)

8. Babazadeh, R., Razmi, J., Rabbani, M., Pishvaee, M.S.: An integrated data envelopment analysis-mathematical programming approach to strategic biodiesel supply chain network design problem. J. Clean. Prod. 147, 694-707 (2017)

9. Bai, Y., Hwang, T., Kang, S., Ouyang, Y.: Biofuel refinery location and supply chain planning under traffic congestion. Transp. Res. Part B Methodol. 45, 162-175 (2011)

10. Ghaderi, H., Pishvaee, M.S., Moini, A.: Biomass supply chain network design: an optimization-oriented review and analysis. Ind. Crops Prod. 94, 972-1000 (2016)

11. Ahn, Y.-C., Lee, I.-B., Lee, K.-H., Han, J.-H.: Strategic planning design of microalgae biomass-to-biodiesel supply chain network: multi-period deterministic model. Appl. Energy 154, 528-542 (2015)

12. Leão, R.R.C.C., Hamacher, S., Oliveira, F.: Optimization of biodiesel supply chains based on small farmers: a case study in Brazil. Bioresour. Technol. 102, 8958-8963 (2011)

13. Ren, J., Tan, S., Yang, L., Goodsite, M.E., Pang, C., Dong, L.: Optimization of emergy sustainability index for biodiesel supply network design. Energy Convers. Manag. 92, 312-321 (2015)

14. Rincón, L.E., Valencia, M.J., Hernández, V., Matallana, L.G., Cardona, C.A.: Optimization of the Colombian biodiesel supply chain from oil palm crop based on techno-economical and environmental criteria. Energy Econ. 47, 154-167 (2015)

15. Orjuela-Castro, J.A., Aranda-Pinilla, J.A., Moreno-Mantilla, C.E.: Identifying trade-offs between sustainability dimensions in the supply chain of biodiesel in Colombia. Comput. Electron. Agric. 161, 162-169 (2018)

16. Awudu, I., Zhang, J.: Uncertainties and sustainability concepts in biofuel supply chain management: a review. Renew. Sustain. Energy Rev. 16, 1359-1368 (2012)

17. De Meyer, A., Cattrysse, D., Rasinmäki, J., Van Orshoven, J.: Methods to optimise the design and management of biomass-forbioenergy supply chains: a review. Renew. Sustain. Energy Rev. 31, 657-670 (2014)

18. Ubando, A.T., Cuello, J.L., El-Halwagi, M.M., Culaba, A.B., Tan, R.R.: Multi-regional multi-objective optimization of an algal biofuel polygeneration supply chain with fuzzy mathematical programming. In: ASME 2014 8th International Conference on Energy Sustainability Collocated with the ASME 2014 12th International Conference on Fuel Cell Science, Engineering and Technology, pp. V002T03A004-V002T03A004. American Society of Mechanical Engineers (2014)

19. Senna, P., Pinha, D., Ahluwalia, R., Guimarães, J.C., Severo, E., Reis, A.: A three-stage stochastic optimization model for the Brazilian biodiesel supply chain. Production 26, 501-515 (2016)

20. Zhang, Y., Jiang, Y., Zhong, M., Geng, N., Chen, D.: Robust optimization on regional WCO-for-biodiesel supply chain under supply and demand uncertainties. Sci. Program. 2016, 1-15 (2016)

21. Mulvey, J.M., Vanderbei, R.J., Zenios, S.A.: Robust optimization of large-scale systems. Oper. Res. 43, 264-281 (1995)

22. Leung, S.C., Wu, Y.: A robust optimization model for stochastic aggregate production planning. Prod. Plan. Control 15, 502-514 (2004)

23. Yu, C.-S., Li, H.-L.: A robust optimization model for stochastic logistic problems. Int. J. Prod. Econ. 64, 385-397 (2000)

24. Pan, F., Nagi, R.: Robust supply chain design under uncertain demand in agile manufacturing. Comput. Oper. Res. 37, 668-683 (2010)

25. An, H., Wilhelm, W.E., Searcy, S.W.: Biofuel and petroleumbased fuel supply chain research: a literature review. Biomass Bioenergy 35, 3763-3774 (2011) 
26. Jetter, A.J.: Educating the Guess: Strategies, Concepts and Tools for the Fuzzy Front End of Product Development. Portland International Center for Management of Engineering and Technology (PICMET), Portland, OR, pp. 261-273 (2003)

27. Varum, C.A., Melo, C.: Directions in scenario planning literature-a review of the past decades. Futures 42, 355-369 (2010)

28. Mietzner, D., Reger, G.: Advantages and disadvantages of scenario approaches for strategic foresight. Int. J. Technol. Intell. Plan. 1, 220-239 (2005)
29. Abbaszadeh, P., Maleki, A., Alipour, M., Maman, Y.K.: Iran's oil development scenarios by 2025. Energy Policy 56, 612-622 (2013)

Publisher's Note Springer Nature remains neutral with regard to jurisdictional claims in published maps and institutional affiliations. 